[Agr. Biol. Chem., Vol. 36, No. 4, p. 658 662, 1972]

\title{
The Aroma of Cigar Tobacco
}

\author{
Part III. Isolation and Synthesis of R-(+)-3-Isopropyl- \\ 5-hydroxypentanoic Acid Lactone ${ }^{\dagger}$ \\ By Hajime Kaneko and Michi Harada \\ Central Research Institute, Japan Monopoly Corporation, \\ Nishi-shinagawa, Shinagazea-ku, Tokyo \\ Received October 12, 1971
}

\begin{abstract}
A minor component of cigar tobacco ( + -3-isopropyl-5-hydroxypentanoic acid lactone (I) was isolated. Synthesis of (+)-I from (+)-limonene established the absolute R-configuration. Stereochemistry of $(+)-I$ is also described.
\end{abstract}

Though several lactones have been added to the number of aroma components of cigar tobacco, ${ }^{1 \sim 41}$ many peaks observed in gas chromatograms of the steam-volatile neutral fraction of cigar tobacco have not been identified. The high polar parts of the steamvolatile neutral fraction particularly consist exclusively of many unidentified minor components, among which some new aroma compounds are thought to exist. In this paper the isolation and synthesis of (+)-3-isopropyl5-hydroxypentanoic acid lactone (I) is described.

A general isolation procedure for aroma components from cigar leaf tobacco is shown in Fig. 1. To obtain a sufficient amount of each minor component for identification, 500 $\mathrm{kg}$ of leaf tobacco was extracted. Of the volatile neutral fractions from steam distillation, Fraction-III had the most fragrant odor (Table I). Silicic acid column chromatography of this fraction is shown in Table II. Fraction-III-14 was rechromatographed with a silicic acid column using benzene-dichloromethane as the eluant. Fraction-III-14-5 to Fraction-III-14-8 contained a liquid with a

+ A part of this work was presented at the Annual Meeting of the Agricultural Chemical Society of Japan, Tokyo, Apr. 2, 1971. fragrant odor as the main component. Preparative gas chromatography of these fractions gave $85 \mathrm{mg}$ of a pure compound (Compound A).

Compound $\mathrm{A}, \mathrm{C}_{8} \mathrm{H}_{14} \mathrm{O}_{2}$, using a high resolution mass spectrum, showed a $\mathrm{R}-\mathrm{C}-\mathrm{O}-\mathrm{R}$ $\mathrm{O}$ group in the infrared portion. In the NMR

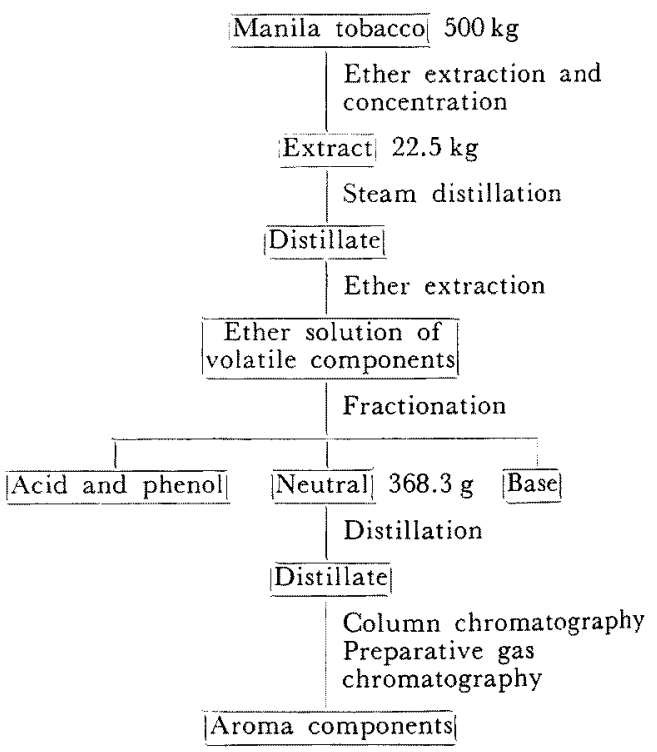

FIG. 1. Isolation Procedure for Aroma Components in Cigar Leaf Tobacco. 
Table 1. Distullation of the Neutral Fraction in Fig. 1

\begin{tabular}{|c|c|c|}
\hline Fraction & Boiling point & rield \\
\hline I & $-32^{\circ} \mathrm{C} / 29 \mathrm{mmHg}$ & $194.3 \mathrm{~g}$ \\
\hline II & $\sim 30^{\circ} \mathrm{C} / 5 \mathrm{mmHg}$ & 8.0 \\
\hline III & $\sim 145^{\circ} \mathrm{C} / 2 \mathrm{mmHg}$ & 44.6 \\
\hline $\mathrm{N}^{*}$ & $1+6-160^{\circ} \mathrm{C}$ & 54.3 \\
\hline V & $161 \sim 165 \mathrm{C}$ & 17.9 \\
\hline VI & $166 \sim 175 \mathrm{C}$ & 8.4 \\
\hline Residue & & 30.3 \\
\hline
\end{tabular}

spectrum an isopropyl group $(\tau 9.06,6 \mathrm{H}(\mathrm{d}))$ and an oxymethylene group $(\tau 5.8,2 \mathrm{H}(\mathrm{m}))$ were indicated. On alkaline permanganate oxidation, Compound A afforded 3-isopropylglutaric acid, whose methylester was identified with an authentic sample. From these data 3-isopropyl-5-hydroxypentanoic acid lactone (I) was suggested as a possible structure for Compound A. I was synthesized from 3-isopropylglutaric acid according to the method of Schumacher et al. ${ }^{5}$ Infrared and mass spectra of the isolated sample were identical with those of the synthetic one.

In general, aliphatic $\gamma$ - or $\delta$-lactones, isolated from natural products as aroma components, contain a $\%$ or $\delta$-alkyl substituents. Therefore, I should be the first $\delta$-lactone having a $\beta$-substituent isolated from nature.

Natural I had a specific rotation of $[\alpha]_{\mathrm{D}}^{20}+$
Table II. Column Chromatography of Fraction-III in TABLE I

Column; Silicic Acid (Mallinkrodt 100 mesh) $7 \mathrm{~cm} \phi \times 47 \mathrm{~cm}$.

\begin{tabular}{|c|c|c|c|c|}
\hline \multirow{2}{*}{ Fraction } & \multicolumn{3}{|c|}{ Solvent } & \multirow{2}{*}{ Yield } \\
\hline & n-Hexane & : Ether & Volume & \\
\hline III -1 & 100 & 0 & 3.0 liter & $20.3 \mathrm{~g}$ \\
\hline III - 2 & 98 & 2 & 1.5 & 0.2 \\
\hline III -3 & 90 & 10 & 1.0 & 4.6 \\
\hline III- 4 & & " & " & 2.6 \\
\hline III- 5 & & " & " & 2.2 \\
\hline$I H-6$ & 80 & 20 & 0.5 & 1.4 \\
\hline III- 7 & & $"$ & $"$ & 1.6 \\
\hline III -8 & & " & $"$ & 1.6 \\
\hline $11-9$ & & $"$ & " & 1.3 \\
\hline III -10 & & " & , & 1.2 \\
\hline III-11 & & " & $r$ & 1.1 \\
\hline III-12 & 50 & 50 & 1.0 & 4.0 \\
\hline III-13 & & , & $"$ & 2.2 \\
\hline III $1+$ & & " & $"$ & 2.6 \\
\hline $111-15$ & 0 & $: \quad 100$ & 1.0 & 3.7 \\
\hline III- 16 & & " & " & 1.5 \\
\hline III 17 & & $"$ & " & 0.3 \\
\hline $111-18$ & Methanol & & 2.0 & 0.9 \\
\hline
\end{tabular}

$16.8^{\circ}$ and showed a plus Cotton effect in its ORD curve. To establish the absolute configuration of this compound, (+)-I was synthesized from $(+)$-limonene using the following procedure (Fig. 2).
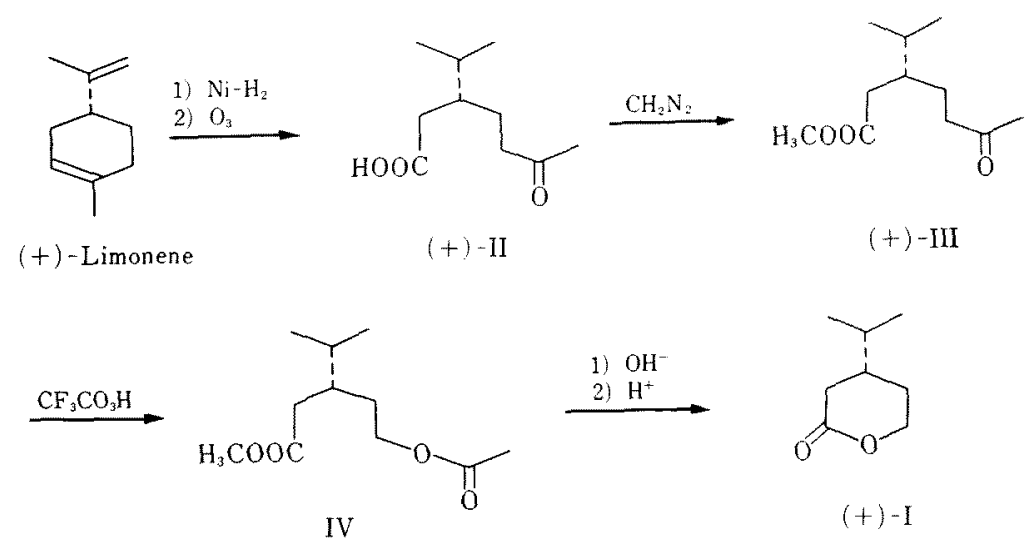

FIG. 2. Schema for the Synthesis of $(+)-3$-Isopropyl-5-hydroxypentanoic Acid Lactone. 
(+)-3-Isopropyl-6-ketoheptanoic acid (II) was prepared from (+)-limonene according to the method of Kataoka and Hanada. ${ }^{6}$ The methyl ester (III) of the acid was treated with perfluoroacetic acid in dichloromethane. On alkaline hydrolysis followed by an acid treatment, the product afforded $(+)$-I which had $[\alpha]_{\mathrm{D}}^{22}+22.4^{\circ}$ in ethanol. The infrared spectrum of synthetic $(+)$-I was identical with that of the natural compound (Fig. 3).

The absolute configuration of $(+)$-limonene has been established as R-configuration ${ }^{7}$; thus, (+)-I must have R-configuration as shown in Fig. 2.

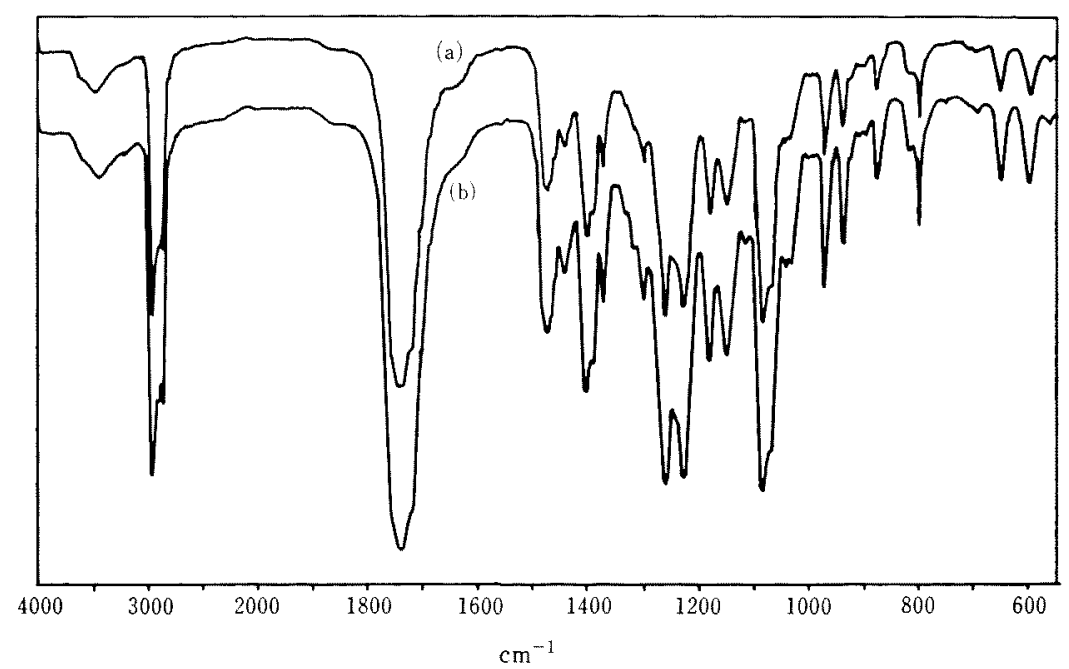

FIG. 3. Infrared Spectra of $(+)$-3-Isopropyl-5-hydroxypentanoic Acid Lactone. (liquid films)
(a) Isolated sample
(b) Synthetic sample

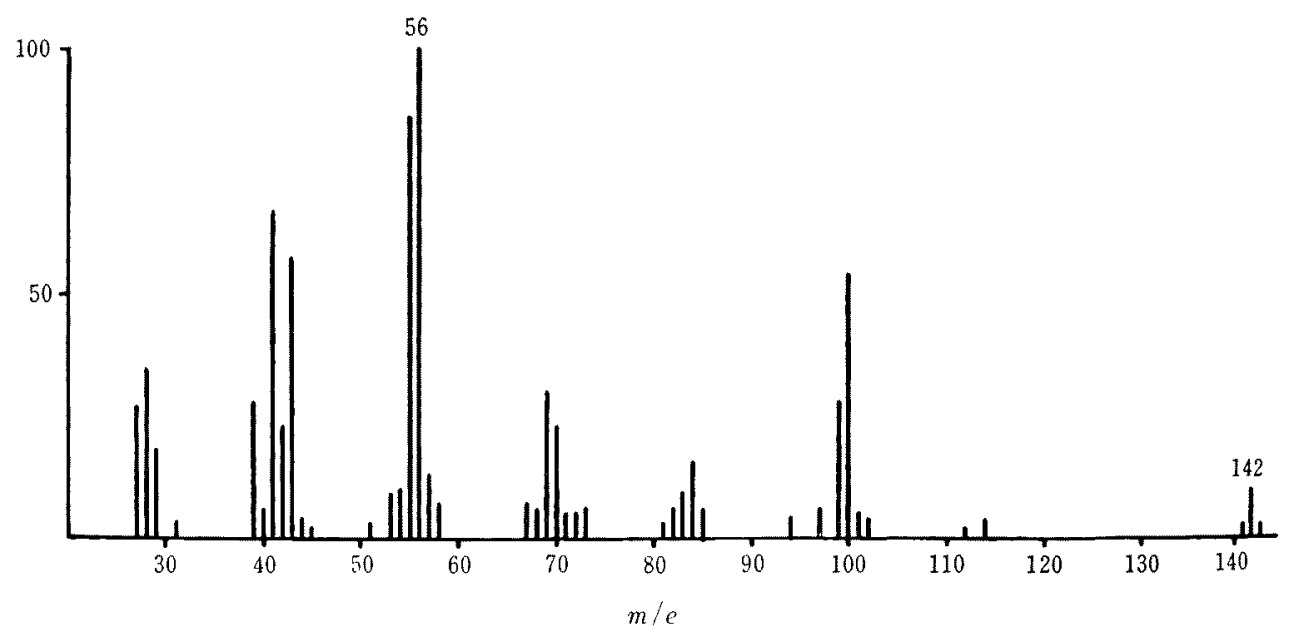

FIG. 4. Mass Spectrum of 3-Isopropyl-5-hydroxypentanoic Acid Lactone. 
Based on X-ray analysis of various saturated $\delta$-lactones, the group $\mathrm{C}-\mathrm{C}-\mathrm{O}-\mathrm{C}$ has been O

shown to be planar. Accordingly the $\delta$-lactone ring exists in boat or half-chair conformations which, in turn, are asymmetric. ${ }^{81}$ Wolf $^{91}$ showed that the sign of the Cotton effect in the ORD curve of $\delta$-lactone was determined by the chirality of the asymmetric boat or half-chair conformation of the $\delta$-lactone ring. Application of Wolf's observation to $(+)-\mathrm{I}$, which has a plus Cotton effect with the first extreme at $235 \mathrm{~m} \mu$, indicates that most of the (+)-I has conformations shown as V or VI.

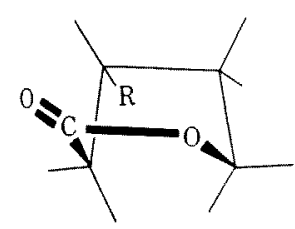

$\mathrm{V}$

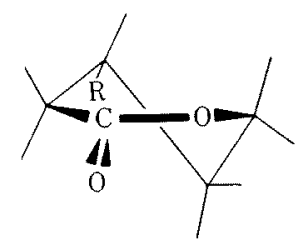

VI<smiles>[R]C[CH]C</smiles>

If not oriented otherwise by certain steric factors, the $\delta$-lactones normally assume the boat conformation. ${ }^{81}$ Therefore, $(+)-\mathrm{I}$ is represented as $\mathrm{V}$. In fact, a comparison of Dreiding models of $\mathrm{V}$ and it's antipode showed that the isopropyl group in the former was sterically less hindered than in the latter.

Both $( \pm)-I$ and $(+)$-I had herbaceous lactone flavors, but the flavor of the racemate was somewhat weaker than that of the $(+)$-enantiomer.

\section{EXPERIMETAL}

Infrared measurements were made with a $\mathrm{JASCO}$ IR-S spectrophotometer. The NMR spectrum was measured with a JNMC-100 in carbon tetrachloride, and the mass spectra with a Hitachi RMU-6E. Specific rotations were measured with a Yanagimoto OR-10 polarimeter and the ORD with a JASCO ORD/UV-5, Gas chromatography was conducted with a Hitachi GC K-53.
Isolation of compound $A$. Five hundred kilograms of chopped cigar leaves (Izabela 2A, 1967 crops in Phillipine) were extracted twice with ether. Evaporation of the ether afforded $22.4 \mathrm{~kg}$ of dark green extract. The extract was steam-distilled. About 12 liters of the distillate was collected for each $100 \mathrm{~g}$ of extract. After saturation with $\mathrm{NaCl}$ the distillate was extracted five times with ether. The combined ether solution of volatile components was successively shaken with $50.6 \mathrm{H}_{2} \mathrm{SO}_{4}$ and $5 \% \mathrm{Na}_{2} \mathrm{CO}_{3}$ solutions to remove acidic and basic fractions, then it was washed with water, dried over anhydrous $\mathrm{Na}_{2} \mathrm{SO}_{4}$ and concentrated using a Widmer column. Thus, $368.3 \mathrm{~g}$ of the neutral fraction which still contained fairly large amounts of ether was obtained. Distillation of the neutral fraction was conducted in a Claisen flask under nitrogen and the distillate was separated into six fractions as shown in Table $I$. Fractions I and II were collected in a dry ice-acetone trap. Gas chromatographic analysis showed that almost all of Fraction-I was ether.

The column chromatography of Fraction-III is shown in Table II. Fraction-III-I4 was rechromatographed with a silicic acid column of $3 \mathrm{~cm} \phi \times 23 \mathrm{~cm}$ hight, then separated into 18 portions using benzenedichloromethane eluants. Gas chromatographic analysis showed Fraction-III-14-5 to Fraction-III-14-8 contained Compound $\mathrm{A}$ as a main peak.

Preparative gas chromatography of the above fractions was carried out under the following conditions. Column: $10 \%$ silicone SE 30 on Diasolid L, $3 \mathrm{~mm} \times$ $3 \mathrm{~m}$, Temperature: $180^{\circ} \mathrm{C}$, Carrier gas: $2 \mathrm{~kg} \mathrm{He} / \mathrm{cm}^{2}$. Under these conditions Compound $A$ had a retention time of $5.8 \mathrm{~min}$ and was collected in a dry ice-acetone trap to afford $85 \mathrm{mg}$ of a liquid.

Spectral data of compound $A$. The infrared and mass spectra of Compound A are shown in Figs. 3 and 4. High resolution mass; $\mathrm{M}^{+}: 142.102$ (Calcd. for $\left.\mathrm{C}_{8} \mathrm{H}_{14} \mathrm{O}_{2} 142.100\right) . \quad[\alpha]_{\mathrm{D}}^{20}+16.8^{\circ}(c=1.19, \mathrm{EtOH})$. ORD $(c=0.030, \mathrm{EtOH})[\alpha]^{18}(\mathrm{~m} \mu):+870^{\circ}(235$, peak $)$, $0^{\circ}(220),-960^{\circ}\left(2 \mathrm{l} 0\right.$, trough). NMR $\tau_{\mathrm{Me}_{4} \mathrm{si}}^{c c 1_{4}}: 9.06$ $(6 \mathrm{H}, \mathrm{d}), 7.38(1 \mathrm{H}), 7.48(1 \mathrm{H}), 5.8(2 \mathrm{H}, \mathrm{m}), 8.0 \sim 8.5$ (4H).

Permanganate oxidation of compound $A$. To a $0.5 \mathrm{ml}$ of $10 \%$ KOH aqueous solution containing $15 \mathrm{mg}$ of Compound $\mathrm{A}$, was dropwise added $5 \%$ aqueous $\mathrm{KMnO}_{4}$ solution untill the color of permanganate ion persisted. The reaction mixture was kept for $1 \mathrm{hr}$ at room temperature. After decomposition of excess 
$\mathrm{KMnO}_{4}$ with $\mathrm{H}_{2} \mathrm{O}_{2}$, the reaction mixture was acidified with dilute $\mathrm{H}_{2} \mathrm{SO}_{4}$, and $\mathrm{MnO}_{2}$ was decomposed by $\mathrm{NaHSO}_{3}$. The aqueous solution was saturated with $\mathrm{NaCl}$ and extracted with ether. Evaporation of the ether afforded a solid, mp $92 \sim 95^{\circ} \mathrm{C}$, IR $1700 \mathrm{~cm}^{-1}$ The solid was esterified with $\mathrm{CH}_{2} \mathrm{~N}_{2}$ then purified by preparative gas chromatography. IR $(2 \mathrm{C}=\mathrm{O} \quad 1740$ $\left.\mathrm{cm}^{-1}\right)$ and mass spectra (parent peak m/e $171 \mathrm{CM}^{+}$ -31 ), base peak m/e 129] of the methyl ester were identical with those of methyl 3-isopropylglutarate. ${ }^{51}$

Synthesis of $(+)$-3-isopropyl-5-hydroxypentanoic acid lactone. (+)-3-Isopropyl-6-ketoheptanoic acid (II) $\left([\alpha]_{\mathrm{D}}^{20}+3.11, c=5.16, \mathrm{EtOH}\right)$ was prepared from $(+)$ limonene $\left([\alpha]_{\mathrm{D}}^{20}+100.0^{\circ}\right.$, neat) according to the method of Kataoka and Hanada. ${ }^{6}$ Treatment of the acid with $\mathrm{CH}_{2} \mathrm{~N}_{2}$ gave a methyl ester (III). Mass; parent peak $m / e 169\left(\mathrm{M}^{+}-31\right)$, base peak $m / e 43 . \quad$ IR; $\nu \mathrm{C}=0$ 1735, $1715 \mathrm{~cm}^{-1} \quad[\alpha]_{\mathrm{D}}^{20}+7.45(c=2.15, \mathrm{EtOH})$.

To a $2.0 \mathrm{~g}$ solution of III in $7.5 \mathrm{ml} \mathrm{CH}_{2} \mathrm{Cl}_{2}, \mathrm{CF}_{3} \mathrm{CO}_{3} \mathrm{H}$ prepared from $0.41 \mathrm{ml}$ of $90 \% \mathrm{H}_{2} \mathrm{O}_{2}$ in $2.5 \mathrm{ml} \mathrm{CH}_{2} \mathrm{Cl}_{2}$ and $2.54 \mathrm{ml}$ trifluoroacetic anhydride was added dropwise. After refluxing the solution for $30 \mathrm{~min}$ on a water bath, the solvent was distilled from the reaction mixture. Without purification, the resulting methyl 5-acetoxy-3-isopropylpentanoate (IV) was hydrolysed with $20 \mathrm{ml}$ of $10 \% \mathrm{KOH}$ at $60^{\circ} \mathrm{C}$ for $1 \mathrm{hr}$. After washing it with ether, the alkaline solution was acidified with dilute $\mathrm{HCl}$ and extracted with ether. After evaporation of the ether, $1 \mathrm{ml}$ of $90 . \mathrm{HCl}$ aqueous solution was added to the residue, which was kept at $70^{\circ} \mathrm{C}$ for $30 \mathrm{~min}$. The reaction mixture was extracted with ether, then the ether layer was washed successively with $5 \% \mathrm{NaHCO}_{3}$ solution and water and dried over anhydrous $\mathrm{Na}_{2} \mathrm{SO}_{4}$. Evaporation of the ether afforded $0.5 \mathrm{~g}$ of $(+)-\mathrm{I}(35 \%$ yield for III). Pure (t)-I was obtained by preparative gas chromatography under the conditions given above. $[\alpha]_{\mathrm{D}}^{22}+22.4^{\circ}(c=2.37, \mathrm{EtOH})$.

Acknowledgements. We wish to express our thanks to Dr. A. Sakurai of the Institute of Physical and Chemical Research for the ORD measurements and to $\mathrm{Mr}$. K. Aizawa of Tokyo University for the NMR measurements.

\section{REFERENCES}

1) H. Kaneko and K. Ijichi, Agr. Biol. Chem., 32, 1337 (1968).

2) H. Kaneko and K. Hoshino, ibid., 33, 969 (1969).

3) H. Kaneko and M. Mita, ibid., 33, 1525 (1969).

4) H. Kaneko, ibid., 35, 1461 (1971).

5) J. N. Schumacher, W. A. Rohde and D. L. Roberts, U.S. Patent, 3380457 (1968).

6) S. Kataoka and I. Hanada, Shonokenkyu, 4, 22 (1952).

7) J. V. Braun und G. Werner, Ber. Deut. Chem. Ges., 62, 1050 (1929).

8) A. Mcl. Mathieson, Tetrahedron Lotters, 1963, 81.

9) H. Wolf, ibid., 1966, 55. 